\title{
Application of Methods of Balance Analysis for the Development of Digital Models for Managing the Production Assets of TPP
}

\author{
Evgeny Lisin ${ }^{1, *}$ Alexandra Parshina ${ }^{1}$ Arina Vasilieva ${ }^{1}$
}

\author{
${ }^{1}$ Department of Economics in Power Engineering and Industry, National Research University "Moscow Power \\ Engineering Institute”, Moscow 111250, Russian Federation \\ *Corresponding author. Email: lisinym@mpei.ru
}

\begin{abstract}
The article examines the possibility of using the methods of balance analysis for the development of digital models for managing the production assets of thermal power plants. It is shown that the balance method is suitable for compiling universal input-output matrices, which can be used for a mathematical description of the expenditure of financial and material resources in the production process of a power plant. An economic and mathematical model of the production assets management system in the form of matrix equations of price, added value, output and supply of energy resources and products is proposed. The developed model provides dual links between economic and technological factors of production and allows organizing the management of production assets of a power plant directly according to the economic effect of their use.
\end{abstract}

Keywords: TPP, production assets, digital management models, methods of balance analysis, economic effect.

\section{INTRODUCTION}

The purpose of asset management is to manage their value, which should be considered as the main indicator of asset quality. In this case, value means the beneficial effect that the owner of the asset can derive from its use. Thus, the owner of the asset does not need the asset itself as such, which is inherently an artifact, but the function that it performs and the value obtained in the process of performing this function. In market conditions, this value can be characterized by the economic effect achieved from the operation of the equipment and the cost of owning this production asset $[1,2]$.

The production assets of thermal power plants in Russia include many units of power equipment interconnected by a single technological process. To ensure reliable and continuous operation of the station, it is necessary to organize the planning of operation, repair and modernization of production assets from the position of increasing their value in production and economic activities. The organizational and methodological support for the implementation of these processes is assigned to the information system for managing production assets.

One of the key problems in building an effective system for managing the production assets of thermal power plants is a high level of capital intensity of fixed assets of generating enterprises associated with the specific nature of the process of generating electricity and heat and supplying it to consumers [3, 4]. Thus, carrying out maintenance, repairs and implementation of programs for modernization and technical re-equipment of the station requires attracting large investments in the context of the existing shortage of financial resources in the industry. Accordingly, special attention should be paid to the economic substantiation of investment programs and projects, prioritizing the inclusion of equipment in investment programs and assessing the risks of their implementation. Incorrect distribution of limited investment funds in programs for technical re-equipment, reconstruction and repairs at TPPs significantly reduces the level of its competitiveness when operating in the conditions of the wholesale electricity and capacity market, leads to an increase in the cost of energy products for consumers and creates a threat of disruption to their stable energy supply.

The use of various scientific and methodological approaches by generating companies to the organization of information systems for managing production assets led to the uneven development TPPs both by territorial location and by year. Due to the fact that more than $68 \%$ of the installed capacity of the stations operates in the unified energy system of the country, a decrease in the operating efficiency of a generating company has a significant impact on the cost and balances of capacity and energy from other producers $[5,6]$.

The industry needs to form a unified methodology for constructing information systems for managing production assets, which should be based on a generalized digital model describing the operation of TPPs from the standpoint of the value of assets used in market conditions 
and the consequences of their disposal at the end of their service life for both the generating company and the energy system as a whole. Structurally, such a model should be suitable for describing the operation of any thermal power plant, and their specificity of operation should be taken into account when choosing the values of the model coefficients.

\section{BACKGROUND}

The main activities of thermal power plants are the production and sale of electricity and heat. In modern market conditions and requirements for ensuring the continuity of power supply, TPPs believe that, on the one hand, each ruble invested in a production asset should be profitable, and on the other hand, it should increase the reliability of equipment operation. Thus, the optimal management of production assets should be built on the basis of the best balance between income and risks of equipment failure.

A complex indicator of effective management of production assets is the economic effect from owning a production asset, which can be determined as the difference between income from the sale of energy products created using the asset and the cost of owning the asset (Figure 1).

The economic effect of owning an asset

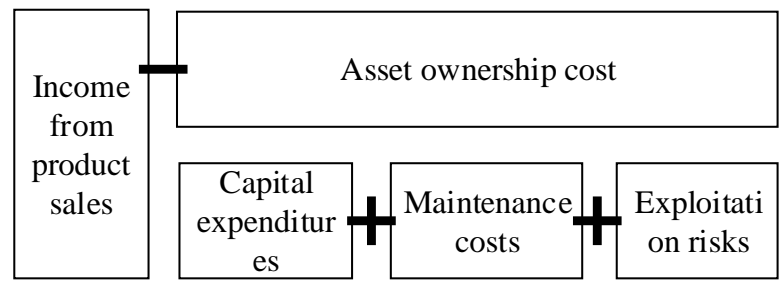

Figure 1 Formation of the economic effect from the operation of the production asset

The cost of owning an asset is determined through such indicators as capital investments in equipment, costs of technical re-equipment, reconstruction and repairs, and also includes operational risks [7, 8]. Risks here mean the amount of economic damage that may arise in the event of equipment failure due to improper maintenance.

To achieve the goals of optimal management of production assets, it is necessary to maximize the economic effect of their operation, which can be achieved by maximizing income from their use while minimizing the cost of ownership.
When building digital models for managing production assets, as a rule, the cyclical nature of the equipment operation process is taken into account.

At the beginning, a description of production assets is carried out, the main business processes of the enterprise and available resources are identified, regulatory and technical documentation is analyzed and the condition of equipment is monitored. The result is systematized data on assets and their technical condition.

Further, on the basis of the data obtained, aggregated technical and economic indicators are calculated and a map of the equipment condition is formed. On its basis, an algorithm for prioritizing equipment is formed to include it in investment programs. A feasibility study of the optimal composition of equipment and the term of work is being carried out.

At the subsequent stages of the formation of a digital model, calendar and resource planning of works and tracking of their implementation are carried out. It is possible to use three approaches to building digital models of TPPs asset management $[9,10]$ :

- Based on the criterion of ensuring a given level of reliability of the operation of power equipment;

- $\quad$ Based on a step-by-step approach;

- Based on the organization of management of the achieved economic effect.

Management according to the criterion of ensuring a given level of reliability of power equipment has a number of limitations associated with the complexity of statistical data analysis. Statistics on failures and changes in the state parameters of a single equipment cannot be obtained, since it presupposes the presence of an array of equipment of the same type operated under the same conditions. At the same time, the main generating equipment at TPPs is unique and designed for different operating modes. This feature of power plants limits the use of statistical methods of the theory of reliability.

The most common is the stepwise approach. At the first stage, the main business processes of TPPs are automated and the storage of information necessary to meet the requirements of regulatory and technical documentation is ensured. At the second stage, reliability management processes are introduced. At the third stage, the transition to managing the cost of ownership of production assets is carried out. At this stage, the costs of operating the equipment are determined, which makes it possible to prioritize equipment replacement in terms of costs. At the last stage, already taking into account the income component from the ownership of production assets, there is a transition to managing the economic 
effect. Here, the profit earned from the operation of a production asset is determined (Figure 2).

Benefits management model

\begin{tabular}{|c|c|c|}
\hline "As-is" model & $\begin{array}{c}\text { Reliability } \\
\text { management } \\
\text { model }\end{array}$ & $\begin{array}{l}\text { Cost of ownership } \\
\text { management model }\end{array}$ \\
\hline
\end{tabular}

Figure 2 A stepwise approach to digitalization of the production asset management system

As the transition from stage to stage, the information model of the production asset management system expands, new information on the production asset and the history of decision-making on its maintenance and modernization are added.

The most difficult, but at the same time extremely important task is the formation of digital management models for the direct economic effect derived from the use of a production asset. When it is known which asset, how much and at what point in time makes a profit, it is possible to quickly develop optimal management decisions to maximize the economic effect while ensuring the necessary requirements for the reliability of equipment operation. The development of such models requires the use of balance analysis methods, which allow linking the production process with the economy of a thermal power plant.

\section{METHODS}

Balance methods are based on the intercomparison of the available material, labor, financial resources and the needs for them in the framework of the production activities of the enterprise.
Mathematically, a balance model is a system of equations that satisfies the requirement of matching the availability of resources and their use. The balance method is necessary to maintain proportions in order to ensure the continuity of production.

The most well-known balance model is the inputoutput balance model, which is used for reasonable planning of input-output flows for given quantities of final products. The development of the input-output balance is associated with the name of the Nobel Prize winner (1973) Leontiev and his proposed model for analyzing input-output interindustry relations [11-13].

Leontief model considers an economy consisting of industries producing one type of product, and the relationship between output and costs is described by linear equations. This model uses a balance sheet consisting of four quadrants that reflect the stages of the production process (Table 1).

The balance sheet is divided into four quadrants. The first quadrant reflects inter-industry material ties in the form of flows, which represent the value of the means of production consumed in the industries, and characterizes the fund for reimbursing material costs. The second quadrant contains the final products of industrial sectors, which go to final consumption and accumulation, and characterizes the material structure of total income. The third quadrant characterizes the total income in terms of its value composition as the sum of net production, including wages and net income of industries. The fourth quadrant reflects the total income created over the period, its final distribution and use. Summing up the balance is the correspondence of the total amount of the created total income in the form of the final product to the volume of the consumed product. Table 2 shows the main characteristics of the input-output balance.

Table 1 Schematic diagram of the input-output balance model

\begin{tabular}{|c|c|c|c|c|c|}
\hline \multirow{2}{*}{$\begin{array}{l}\text { Producing } \\
\text { industries }\end{array}$} & \multicolumn{3}{|c|}{ Consuming industries } & \multirow[t]{2}{*}{ Final product } & \multirow{2}{*}{$\begin{array}{c}\text { Gross } \\
\text { product }\end{array}$} \\
\hline & 1 & $\mathrm{j}$ & $\mathrm{n}$ & & \\
\hline 1 & $x_{11}$ & $x_{l j}$ & $x_{1 n}$ & $Y_{1}$ & $X_{1}$ \\
\hline$\ldots$ & & I & & II & $\ldots$ \\
\hline$i$ & $x_{i 1}$ & $x_{i j}$ & $x_{i n}$ & & $X_{i}$ \\
\hline$\ldots$ & & & & & $\ldots$ \\
\hline$n$ & $x_{n 1}$ & $x_{n j}$ & $x_{n n}$ & $Y_{n}$ & $X_{n}$ \\
\hline Wages & $v_{1}$ & III & $\overline{v_{n}}$ & IV & - \\
\hline Net income & $m_{1}$ & $m_{j}$ & $m_{n}$ & $m_{k}$ & - \\
\hline Gross product & $\overline{X_{1}}$ & $X_{j}$ & $\overline{X_{n}}$ & - & $\sum_{i=1}^{n} X_{i}=\sum_{j=1}^{n} X_{j}$ \\
\hline
\end{tabular}


Table 2 Mathematical expressions of the main characteristics of the input-output balance

\begin{tabular}{|c|c|}
\hline Characteristic & Mathematical expression \\
\hline $\begin{array}{c}\text { Cost structure of production sectors } \\
\text { Balance between production and } \\
\text { consumption }\end{array}$ & $X_{j}=\sum_{i=1}^{n} x_{i j}+\left(v_{j}+m_{j}\right), j=\overline{1, n}$ \\
\hline $\begin{array}{c}\text { Equality of total net production and final } \\
\text { product }\end{array}$ & $X_{i}=\sum_{j=1}^{n} x_{i j}+Y_{i}, i=\overline{1, n}$ \\
\hline \begin{tabular}{c} 
Intermediate product $\left(v_{j}+m_{j}\right)=\sum_{i=1}^{n} Y_{i}$ \\
\hline Technological matrix
\end{tabular} & $X=\sum_{i=1}^{n} \sum_{j=1}^{n} x_{i j}$ \\
\hline Input-output model & $A=\left(a_{i j}\right)^{n, n}, a_{i j}=\frac{x_{i j}}{X_{j}}$ \\
\hline
\end{tabular}

The analysis of scientific works on the use of the balance method for compiling input-output matrices demonstrates its versatility and efficiency [11-16]. Consequently, it can be used to describe the processes of TPP functioning by creating a single matrix model describing both economic and technological processes of TPPs. This will make it possible to form a digital model of power plant asset management in terms of the economic effect derived from their use.

The technological structure of a TPP can be represented by three main blocks: an electric generator, a steam turbine and a boiler unit [17- 19]. An electric generator receives energy from mechanical motion from a steam turbine, which in turn receives energy from a boiler unit. This forms the basis of a three-tier matrix representation of TPPs (Figure 3).

III

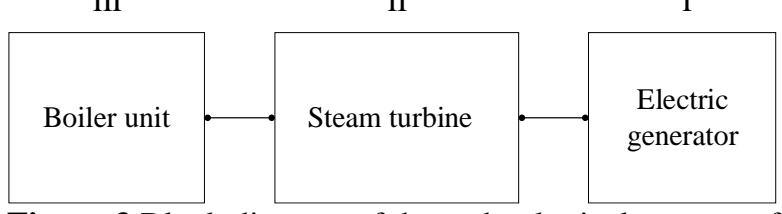

Figure 3 Block diagram of the technological process of a TPP power unit

The TPP control space can be divided into subspaces of financial and production resources. Production resources include technical production systems, and financial resources - revenue, payment of labor resources and profit.

The output and price of energy products is described by linear algebraic equations "price - costs - added value" for financial resources and "output - costs - supply" for material resources spent in the production process. The result is two systems of linear algebraic equations with unknown prices and supplies of energy products, and the number of unknowns and the number of equations are equal. For compact writing and solving a system of linear algebraic equations, you can use matrices for financial and production resources.

Thus, the balance modeling method allows one to obtain matrix models of financial and production processes of TPPs and to study the mutual influence of production technology and financial activities of a generating company.

In practice, the structure of the production assets of a generating company is complex and multidimensional, the equipment of a power plant is linked to each other by a web of mutual costs and expenses. Arbitrarily allocating a group of assets and discarding the rest of the equipment will lead to the break of these connections and the occurrence of management errors. This can be avoided only by building a complete matrix of TPP equipment with the utmost detailing of mutual relations.

The balance method allows partitioning the control space into subspaces, and the control result does not depend on the number of subspaces in the partition. Therefore, any group of TPP equipment can be separated from the complete matrix by sectioning. In this case, the discarded links do not disappear, but are mathematically precisely added to the remaining links of the TPP. Sectioning should correspond to the selected structure of the TPP technological process.

\section{RESULTS AND DISCUSSION}

The application of the considered balance method allowed us to propose a digital model for managing the production assets of thermal power plants. 
The model is based on matrix analysis of the production asset management system, which can be set in the form of the following equations:

$$
\left\{\begin{array}{l}
\left(1-A_{i k}\right) p_{k}=v_{i} \\
v_{i}=r_{i}+w_{i} \\
\left(1-B_{i k}\right) y_{k}=c_{i}
\end{array},(1)\right.
$$

where $A_{i k}, B_{i k}$ - matrices of costs of financial and material resources, $p_{k}, v_{i}$ - price and value added per unit of energy, $r_{i}$ - profit, $w_{i}$ - payment of labor resources, $y_{k}-$ energy output of the $k$-th sector, $c_{i}$ - energy supply of the $i$-th sector.

The first equation is the equation of financial resources costs. The second equation describes the structure of value added, consisting of profits and labor costs. The third equation reflects the output-supply of material resources, which are the production assets of the enterprise.

The matrix of costs of financial resources is a transposed matrix of costs of material resources $B_{i k}=$ $\left(A_{i k}\right)^{\mathrm{T}}$. This reveals the duality of the spaces for managing the financial and production assets of the enterprise.

Based on the equations made and the known cost of a unit of energy supplied to consumers in each sector of the control space, it is possible to determine the added value, as well as the profit and payment of labor resources of the allocated sectors. Similarly, from the known values of the energy output of each sector of the control space, it is possible to determine the volumes of energy supply supplied to consumers

The inverse problem can be solved in accordance with the following equations:

$$
\left\{\begin{array}{l}
p_{k}=\left(1-A_{k i}\right)^{-1} v_{i} \\
v_{i}=r_{i}+w_{i} \\
y_{k}=\left(1-B_{k i}\right)^{-1} c_{i}
\end{array}\right.
$$

The cost of energy $p_{k}$ is equal to the sum of the added value $v_{i}$ multiplied by the matrix of expenditures of financial resources. The energy output $y_{k}$ is determined by the sum of the energy output of the sectors $c_{i}$ multiplied by the matrix of material resources costs.

These equations allow for the known value of the price of energy resources to determine the added value, which should be established in order to ensure the required level of profit, and according to the volume of supply to energy consumers, each sector can determine the plan for their production.

Cost matrices describe the structure of energy costs of a thermal power plant included in the conditionally variable costs. These costs have the following structure:
- $\quad$ Purchased electricity (power);

- Heat transfer services;

- Water for technological needs.

- Value added includes profits, labor costs and conditionally fixed costs.

The conditionally fixed costs of TPPs include:

- Depreciation of fixed assets and assets

- Works and services of an operational type;

- Insurance premiums, taxes and fees;

- Other expenses related to product sales.

The resulting matrix equations of price and value added, output and supply of energy make it possible to dually relate economic factors of production (added value, profit, payment of labor resources) and technological processes of electricity and heat production at TPPs. Thus, a solution to the problem of organizing the management of production assets will be achieved directly according to the economic effect of their use.

\section{CONCLUSIONS}

Overall, production asset management is one of the key elements of the economy of a generating enterprise. It is worth striving to build a system of asset exploitation based on management directly according to the economic effect. This can be done through the development of digital models for managing the financial and material resources of the power plant.

The results of the study of the input-output balance model showed that this dynamic balance model can be adapted to build a digital model of the production activity of TPPs, which will allow linking the characteristics of the technological process of energy production and the economic indicators of the thermal power plant.

The use of the balance method made it possible to mathematically describe the production asset management system in the form of matrix equations of price, value added, output and supply of energy resources and products. The developed model provides dual links between economic and technological factors of production, which allows organizing the management of power plant assets from the standpoint of the best ratio of income from their use and the cost of maintaining reliability.

\section{ACKNOWLEDGMENTS}

This work was performed under the project PNI 2020/22.

- $\quad$ Fuel costs (gas, coal, fuel oil, other fuel); 


\section{REFERENCES}

[1] L.D. Gitelman, M.V. Kozhevnikov, D.D. Kaplin, Asset management in grid companies using integrated diagnostic devices, International Journal of Energy Production and Management 4(3) (2019) 230-243. DOI: https://doi.org/10.2495/eq-v4-n3-230-243

[2] S. Petchrompo, A.K. Parlikad, A review of asset management literature on multi-asset systems, Reliability Engineering \& System Safety 181 (2019) 181-201. DOI: https://doi.org/10.1016/j.ress.2018.09.009

[3] E. Lisin, P. Okley, A. Zielińska, Institutional determinants of thermal power sector economic productivity, Journal of Institutional Studies 11(1) (2019) 144-154. DOI: https://doi.org/10.17835/20766297.2019.11.1.144-154

[4] E. Lisin, D. Shuvalova, I. Volkova, W. Strielkowski, Sustainable development of regional power systems and the consumption of electric energy, Sustainability 10(4) (2018) 1111. DOI: https://doi.org/10.3390/su10041111

[5] E. Lisin, Y. Marishkina, W. Strielkowski, D. Streimikiene, Analysis of competitiveness: energy sector and the electricity market in Russia, Economic researchEkonomska istraživanja 30(1) (2017) 1820-1828. DOI: https://doi.org/10.1080/1331677X.2017.1392887

[6] F.V. Veselov, I.V. Erokhina, A.S. Makarova, A. A. Khorshev, Comprehensive assessment of the effective scope of modernization of thermal power plants to substantiate the rational structure of the generating capacities for the future until 2035, Thermal engineering, 64(3) (2017) 161-169. DOI: https://doi.org/10.1134/S0040601517030107

[7] I. Roda, M. Macchi, S. Albanese, Building a Total Cost of Ownership model to support manufacturing asset lifecycle management, Production Planning \& Control 31(1) (2020) 19-37. DOI: https://doi.org/10.1080/09537287.2019.1625079

[8] P. E. Love, J. Matthews, The 'how'of benefits management for digital technology: From engineering to asset management, Automation in Construction 107 (2019) $102930 . \quad$ DOI: https://doi.org/10.1016/j.autcon.2019.102930

[9] P. Okley, Leading prospects for the development of production asset management systems of Russian thermal power plants, in: Proceedings of the 3rd International Conference on Social, Economic, and Academic Leadership (ICSEAL 2019), Atlantis Press, 2019, pp. 361-365. DOI: https://doi.org/10.2991/icseal19.2019 .56
[10] M. Pasetti, S. Rinaldi, D. Manerba, A virtual power plant architecture for the demand-side management of smart prosumers, Applied Sciences 8(3) (2018) 432. DOI: https://doi.org/10.3390/app8030432

[11] A. Slavianov, Balance model of resource support of innovative development programs, International Journal of Professional Science (11) (2019) 6-9.

[12] I. Naumov, Scenario model of reproduction of the financial potential of institutional sectors as a tool for forecasting the economic sustainability of regional systems, in: E3S Web of Conferences, vol. 208, EDP Sciences, 2020, 03008 p. DOI: https://doi.org/10.1051/e3sconf/202020803008

[13] Y.N. Ivanov, V.V. Tokarev, Innovation efficiency range estimates by balance models, Automation and Remote Control 79(10) (2018) 1823-1835. DOI: https://doi.org/10.1134/S0005117918100077

[14] I. Potravny, A. Gusev, V. Stoykov, V. Gassiy, Modification of the Leontief-Ford input-output model for the green economy goals and environment protection, Journal of Geoscience and Environment Protection 5(11) (2017) 15. DOI: https://doi.org/10.4236/gep.2017.511002

[15] M. Kozicka, A novel approach to stochastic input-output modeling, RAIRO-Operations Research, 53(4) (2019) 1155-1169. DOI: https://doi.org/10.1051/ro/2018046

[16] V.V. Ivanter, Role of Input-Output Model in Macroeconomic Analysis and Forecasting, Studies on Russian Economic Development 29(6) (2018) 581-583. DOI: https://doi.org/10.1134/S1075700718060047

[17] E. Lisin, G. Kurdiukova, W. Strielkowski, Economic prospects of the power-plant industry development in Russia, Journal of International Studies 9(3) (2016) 178-190. DOI: https://doi.org/10.14254/2071$8330.2016 / 9-3 / 14$

[18] A. Askarzadeh, M. Gharibi, Accurate estimation of cost function parameters for thermal power plants using a novel optimization approach, Energy Sources, Part A: Recovery, Utilization, and Environmental Effects 40(24) (2018) 2986-2999. DOI: https://doi.org/10.1080/15567036.2018.1514440

[19] N. Fedorova, Y. Shcheglov, P. Kobylyackiy, Application of IDEF0 functional modeling methodology at the initial stage of design the modernization of TPP in ETC, in: E3S Web of Conferences, vol. 209, EDP Sciences, 2020. 03013 p. DOI: https://doi.org/10.1051/e3sconf/202020903013 